Supplement of SOIL, 7, 15-31, 2021

https://doi.org/10.5194/soil-7-15-2021-supplement

(c) Author(s) 2021. This work is distributed under

the Creative Commons Attribution 4.0 License.

(c) (1)

Supplement of

\title{
Spatial variability in heavy metal concentration in urban pavement joints - a case study
}

\section{Collin J. Weber et al.}

Correspondence to: Collin J. Weber (collin.weber@geo.uni-marburg.de)

The copyright of individual parts of the supplement might differ from the CC BY 4.0 License. 

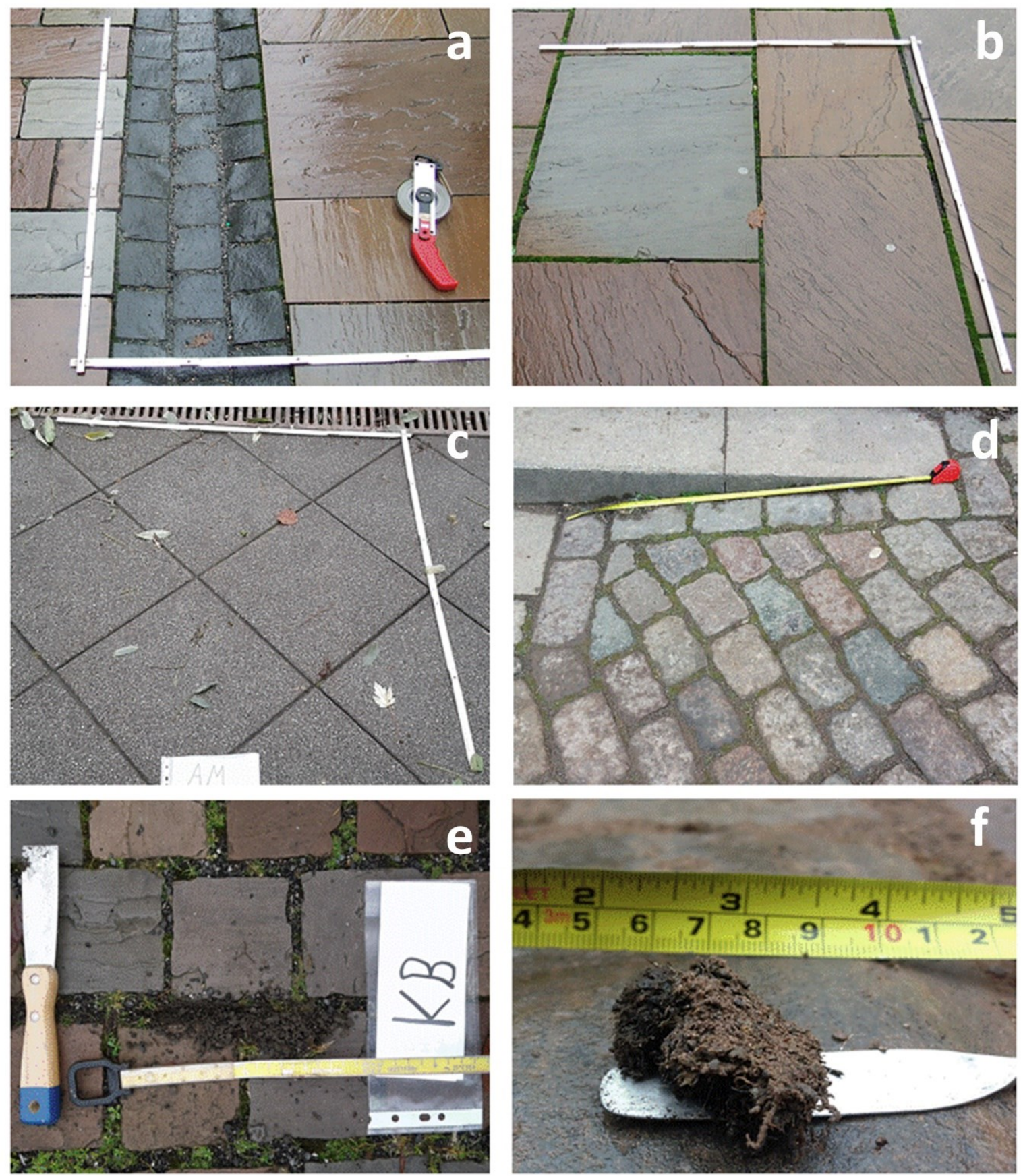

Figure S1: Pavement types and joints at different sampling sites. a) One square meter sampling point at sampling site $\mathrm{ZH}$ with street drainage channel (sandstone and basalt pavement); b) One square meter sampling point at sampling site EK (sandstone pavement); c)

One square meter sampling point at sampling site AM with drainage gutter (concrete pavement); d) Sampling point at site MP with slope and mixed pavement types; e) Pavement joints between sandstone pavement at sampling site KB; f) Pavement joint substrate at sampling site MP. Pictures taken by Alexander Santowski (2017). 

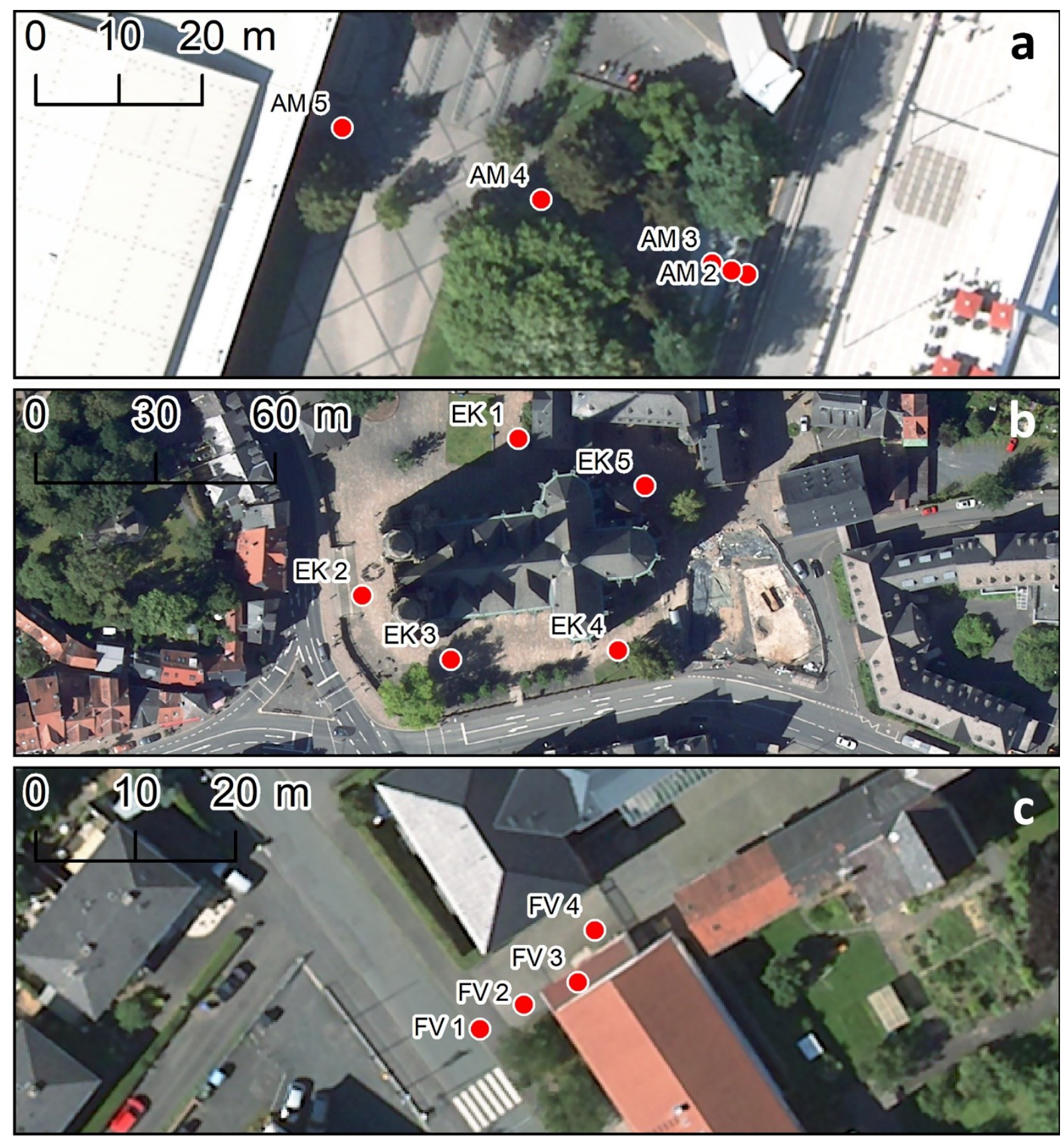

Figure S2a: Detailed maps of single sampling sites located in the inner city of Marburg (Hesse). a) Sampling site AM with linear sampling points from main street (right); b) Sampling site EK with sampling points scattered around the central church and surrounded by two major streets; c) Sampling site FV with linear sampling points from secondary road. Background airborne image (DOP20): (C) Hessian administration for soil management and geoinformation (2020). 

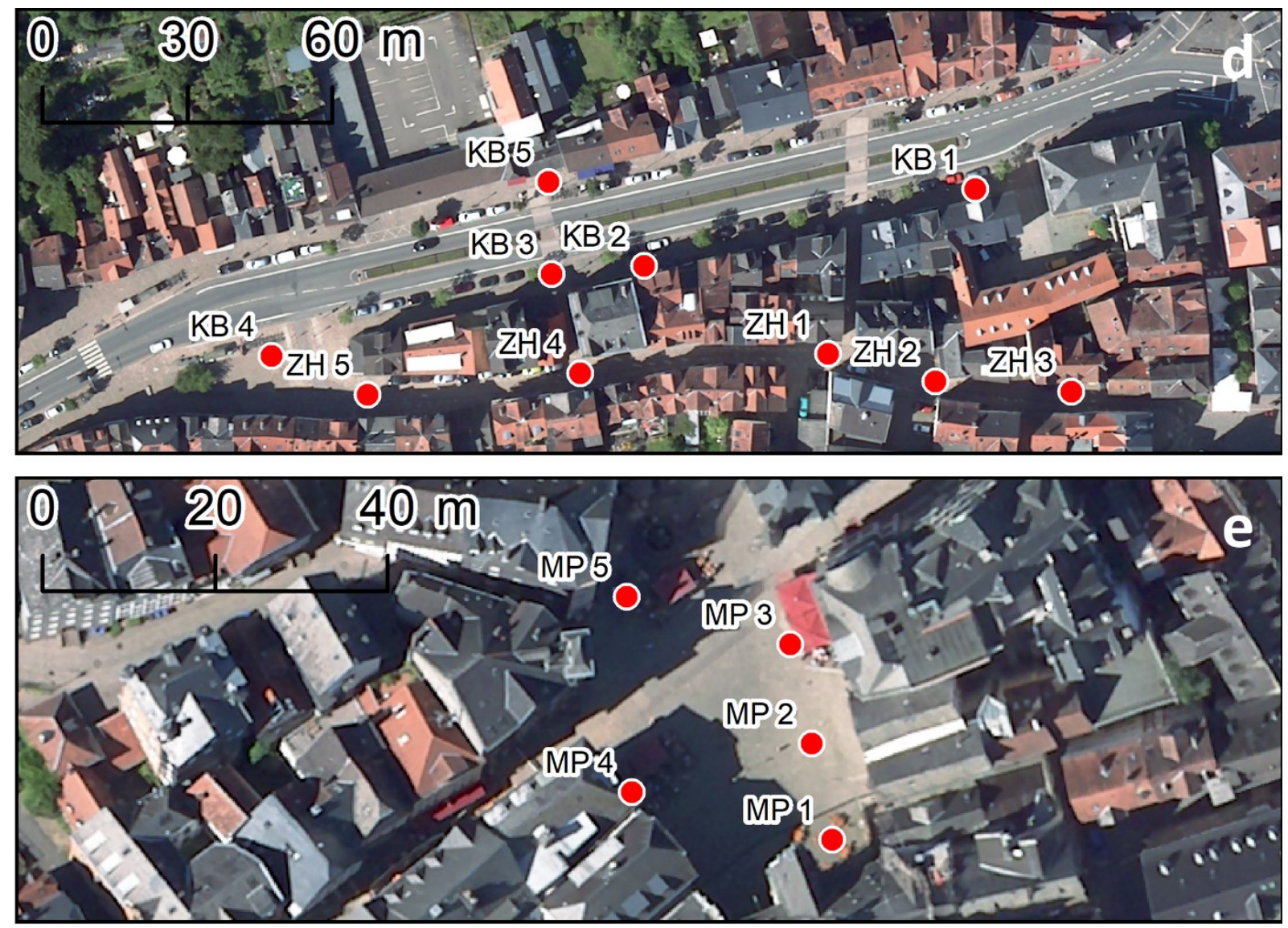

Figure S2b: Detailed maps of single sampling sites located in the inner city of Marburg (Hesse). d) Sampling sites KB (scattered on sidewalks around the major street "Ketzerbach") and ZH located on the secondary traffic-calmed road "Zwischenhausen"; e) Sampling site MP with sampling points scattered on the historic marked place in the inner-city centre (trafficcalmed area). Background airborne image (DOP20): (C) Hessian administration for soil management and geoinformation (2020). 